\title{
ANTICORPOS PARA OS VIRUS DA RUBEOLA, DO SARAMPO E DA CAXUMBA EM CRIANÇAS DE SÃO PAULO, BRASIL *
}

Renato Piza de Souza Carvalho** Alfred S. Evans ***

Luitgard Grossmann****

Cláudio Sérgio Pannuti ****

Carvalho, R. P. de S. et al. - Anticorpos para os vírus da rubéola, do sarampo e da caxumba em crianças de São Paulo, Brasit. Rev. Saúde públ., S. Paulo, 10:279-84, 1976.

RESUMO: Foram dosados anticorpos inibidores da hemaglutinaçāo para o vírus da rubéola, do sarampo e da caxumba, em amostras de soro de 166 crianças de elevado nivel sócio-econômico, com idade de 6 a 12 anos, que freqüentavam, em 1969, uma escola primária na cidade de São Paulo, Brasil. A percentagem de soros positivos foi de $49,3 \%$ para a rubéola, $88,2 \%$ para o sarampo e $79,4 \%$ para a caxumba. Através de interrogatório junto aos pais, observou-se significativa correspondência entre antecedentes clínicos positivos para sarampo e caxumba e presença de anticorpos circulantes $195,3 \%$ e $91,7 \%$, respectivamente). Houve grande discordancia quando os antecedentes clinicos ou vacinais para sarampo e caxumba eram negativos: $51,8 \%$ e $61,4 \%$ destas crianças possuiam anticorpos circulantes. Quanto à rubéola, não foi possivel fazer-se tal correlação, pois a maioria das mães não sabia dar informaçōes sobre esta doença, no passado.

UNITERmos: Inquérito sorológico. Sarampo. Rubéola. Caxumba.

\section{IN T ROD U C $\AA$}

Ultimamente, tem sido pesquisada, em vários países, a incidência na população normal, dos anticorpos (Ac) contra os vírus da rubéola ${ }^{9,11,15,16}$, do sarampo ${ }^{1}$, 9, 10, 20 e da caxumba ${ }^{2,9,18}$, existindo também no Brasil alguns estudos nesse sentido $3,4,5,8,14,17,19,21,22,23$.
Os inquéritos sorológicos têm grande interesse prático porque possibilitam uma visão mais precisa da verdadeira importância dessas viroses em cada comunidade, já que os dados epidemiológicos obtidos através de comunicações aos órgãos de Saúde Pública são falhos, tanto pela

* Realizado com suporte parcial de bolsas da Brown Hazen Fund, Research Corporation, New York e da CA 12952 do National Institute of Health.

* Do Instituto de Ciências Biomédicas da USP. Departamento de Microbiologia e Imunologia; do Instituto de Medicina Tropical de São Paulo - Av. Dr. Enéas de Carvalho Aguiar s/n - São Paulo, SP - Brasil.

** Do Department of Epidemiology and Public Health, Yale University - School of Medicine, New Haven, Connecticut - USA.

*** Do Instituto de Medicina Tropical de São Paulo - Av. Dr. Enéas de Carvalho Aguiar s/n - São Paulo, SP - Brasil. 
CARVAlHo, R. P. de $\mathrm{S}$. et al. - Anticorpos para os virus da rubéola, do sarampo e da caxumba em crianças de São Paulo, Brasil. Rev. Saúde públ., S. Paulo, 10:279-84, 1976.

omissão na notificação, quanto pela existência de casos atípicos ou subclínicos que dificultam bastante o diagnóstico correto $^{2,7}, 8,11,12,13,18,20$.

Hoje em dia a disponibilidade de vacinas contra estas moléstias fez aumentar a importância de um planejamento adequado do programa de imunizaçōes, no qual o perfeito conhecimento do perfil epidemiológico da região deve ocupar lugar de destaque.

O objetivo deste trabalho é avaliar a incidência dos anticorpos contra $o$ vírus da rubéola, do sarampo e da caxumba, em crianças normais da cidade de São Paulo.

\section{MATERIAL E METODOS}

Foram pesquisados anticorpos circulantes para rubéola (144) soros), sarampo (162 soros) e caxumba (14l soros), em 166 crianças de 6 a 12 anos, que freqüentavam uma escola primária particular, na cidade de São Paulo, no ano de 1969. A clientela dessa escola é considerada como sendo de nível sócio-econômico elevado, usando como critério a profissão dos pais (industriais, profissionais liberais e grandes comerciantes).

0 sangue foi colhido em jejum e, após separação do soro, mantido a $-20^{\circ} \mathrm{C}$ até o seu uso.

Dosaram-se, através de microtécnica, os anticorpos inibidores da hemaglutinação para os três vírus, sendo considerados positivos os soros que inibiam a hemaglutinação na diluição de $1 / 10$ ou maior.

Através de interrogatório, junto aos pais, procurou-se avaliar a concordância entre antecedentes clínicos positivos ou negativos, para as três doenças e presença de anticorpos circulantes no sangue.

\section{RESULTADOS}

Rubéola: Os resultados obtidos indicaram que $50,7 \%$ das crianças do grupo etário de 6-12 anos não tinham Ac inibidores da hemaglutinação detectáveis no sangue.

A distribuição das percentagens de positividade, segundo vários grupos etários, pode ser vista na Tabela 1 .

$$
\text { TA BELA } 1
$$

Distribuição, segundo a idade, da presença de anticorpos inibidores da hemaglutinação para o vírus da rubéola, em crianças de uma escola primária do municipio de São Paulo - 1969

\begin{tabular}{r|r|r|r|c}
\hline $\begin{array}{r}\text { Idade } \\
\text { (anos) }\end{array}$ & $\begin{array}{c}\text { Posi- } \\
\text { tivos }\end{array}$ & $\begin{array}{c}\text { Nega- } \\
\text { tivos }\end{array}$ & Total & $\begin{array}{c}\text { Percenta- } \\
\text { gem de } \\
\text { positivos }\end{array}$ \\
\hline 6 & 7 & 6 & 13 & 53,8 \\
7 & 13 & 12 & 25 & 52,0 \\
8 & 12 & 19 & 31 & $\mathbf{3 8 , 7}$ \\
9 & 16 & 14 & 30 & $\mathbf{5 3 , 3}$ \\
10 & 15 & 16 & 31 & 48,3 \\
11 & 6 & 5 & 11 & $\mathbf{5 4 , 5}$ \\
12 & 2 & 1 & 3 & 66,6 \\
\hline
\end{tabular}

Não foi possível correlacionar antecedentes positivos para a doença com presença ou ausência de anticorpos circulantes, porque a grande maioria dos pais não sabia dar informações a respeito de rubéola no passado.

Sarampo: No grupo etário estudado, $88,2 \%$ das 162 crianças possuíam anticorpos inibidores da hemaglutinação. Entretanto, 28 destas $(17,2 \%)$ tinham sido vacinadas contra o sarampo, e se estas fossem retiradas do grupo, a percentagem de positividade cairia para $86,5 \%$.

A distribuição das percentagens de positividade, segundo vários grupos etários, pode ser vista na Tabela 2.

De 107 crianças não vacinadas, com história de sarampo no passado, 102 apresentaram Ac inibidores da hemaglutina- 
Carvalho. R. P. de $S$. et al. - Anticorpos para os virus da rubéola, do sarampo e da caxumba em criancas de são Paulo. Brasil. Rev Sañde públ., S. Paulo, 10:279-84, 1976.

TA B L A 2

Distribuição. segundo a ldade, da presenca de anticorpos inibidores da hemaglutinação para o virus do sarampo, em crianças de uma escola primária do município de são Paulo - 1969

\begin{tabular}{r|rrrr}
\hline $\begin{array}{l}\text { Idade } \\
\text { (anos) }\end{array}$ & $\begin{array}{c}\text { Posi- } \\
\text { tivos }\end{array}$ & $\begin{array}{c}\text { Nega- } \\
\text { tivos }\end{array}$ & Total & $\begin{array}{c}\text { Percenta- } \\
\text { gem de } \\
\text { positivos }\end{array}$ \\
\hline 6 & 14 & 1 & 15 & 93,3 \\
7 & 26 & 5 & 31 & 83,8 \\
8 & 27 & 5 & 32 & 84,3 \\
9 & 30 & 2 & 32 & 93,7 \\
10 & 30 & 5 & 35 & 85.7 \\
11 & 13 & 1 & 14 & 98,5 \\
12 & 3 & 0 & 3 & 100.0 \\
\hline & & & & \\
\hline
\end{tabular}

ção detectáreis para este vírus no soro. havendo portanto uma correspondência da ordem de $95.3 \%$.

Por outro lado, quando se comparou ausência de história de sarampo ou racinação no passado, o que ocorreu somente em 27 crianças, com presença de anticorpos circulantes, observamos uma discordância da ordem de $51.8 \%$.

Das 28 crianças vacinadas, 27 tinham Ac circulantes detectáveis $(96,4 \%)$ e em 6 delas $(21,4 \%)$ havia história clínica de sarampo no passado.

Caxumba: Os resultados obtidos na pesquisa de anticorpos inibidores da hemaglutinação contra o vírus da caxumba foram de certa forma semelhantes aos encontrados no sarampo: $79.4 \%$ de 141 crianças que não tinham tomado vacina contra este rírus possuíam anticorpos circulante:

A distribuição das percentagens de positividade, segundo vários grupos etários. pode ser vista na Tabela 3.

Em 84 crianças com história de caxumba no passado. constatou-se presença de anticorpos circulantes em 77 , havendo,
TABLA 3

Distribuição, segundo a idade, da presença de antıcorpos inibıdores da hemaglutinação para o virus da caxumba, em crianças de uma escola primárla do município de sāo Paulo - 1969

\begin{tabular}{|c|c|c|c|c|}
\hline $\begin{array}{l}\text { Idade } \\
\text { (anos) }\end{array}$ & $\begin{array}{l}\text { Posi- } \\
\text { tivos }\end{array}$ & $\begin{array}{l}\text { Nega- } \\
\text { tivos }\end{array}$ & Total & $\begin{array}{l}\text { Percenta- } \\
\text { gem de } \\
\text { positivos }\end{array}$ \\
\hline 6 & 13 & 1 & 14 & 92,8 \\
\hline 7 & 19 & 7 & 26 & 73,0 \\
\hline 8 & 23 & 5 & 28 & 82,1 \\
\hline 9 & 24 & 7 & 31 & 77,4 \\
\hline 10 & 22 & 7 & 29 & 75,8 \\
\hline 11 & 9 & 2 & 11 & 81,8 \\
\hline 12 & 2 & 0 & 2 & 100,0 \\
\hline Total & 112 & 29 & $1+1$ & 79,4 \\
\hline
\end{tabular}

portanto. uma concordancia de $91,6 \%$ entre estes dois eventos.

Quando se comparou a ausência de vacinação ou de história de caxumba clinicamente manifesta no passado (57 crianças), com presença de anticorpos inibidores da hemaglutinação circulantes, foi encontrada uma discordância da ordem de $61,4 \%$, pois em 35 destas a pesquisa foi positiva.

\section{DISCUSSAO}

A existência de suscetibilidade à infecçāo pelo vírus da rubéola, em $49,3 \%$ das crianças de 6 a 12 anos estudadas, confirma os resultados encontrados por Rizzato ${ }^{17}$, em 1973, que não conseguiu demonstrar anticorpos inibidores da hemaglutinação em $47,3 \%$ dos soros de escolares de 6.5 a 8 anos analisados. Considerando que Cotillo ${ }^{4}$, dosando anticorpos neutralizantes em mulheres grávidas de 15 a 44 anos. de baixo nível sócio-econômico. encontrou $22.8 \%$ de susceptíveis, e que Candeias e Rosenburg ${ }^{3}$, dosando anticorpos inilidores da hemaglutinação em 415 soros de professoras do município de São Paulo. encontraram $32.1 \%$ com títu- 
CARVAlHo, R. P. de $S$. et al. - Anticorpos para os virus da rubéola, do sarampo e da caxumba em criancas de São Paulo, Brasil. Rev. Saúde públ., S. Paulo, 10:279-84, 1976.

los menores do que 8, parece-nos evidente que existem condições em nosso meio para o aparecimento de embriopatias provocadas pelo vírus da rubéola, através da infecção de mulheres nos primeiros meses de gestação. Devemos ressaltar entretanto, que a taxa de susceptíveis pode apresentar grandes variaçōes de acordo com - tipo de população estudada, pois sabe-se hoje que a aquisição das viroses respiratórias se dá mais precocemente em condições que facilitem a disseminação viral, a partir das secreçōes dos doentes, como ocorre em populações fechadas (creches, quartéis, etc.) e de baixo nível sócio-econômico. Este fato pode ser comprovado através da comparação de nossos resultados com estudos sorológicos realizados por outros autores em ambientes diversos. Assim, enquanto $51,6 \%$ das crianças de 6 a 9 anos por nós estudadas ainda era susceptível, Schatzmayr e Mesquita ${ }^{10}$, analisando crianças da mesma faixa etária, residentes em um parque proletário do Rio de Janeiro, em 1969, encontraram $32,9 \%$ de susceptiveis através de pesquisa de anticorpos inibidores da hemaglutinação, e Veronesi e col. ${ }^{23}$ utilizando a mesma técnica, estudaram em 1969, cem crianças de uma creche de São Paulo, com média etária de 7 anos e 5 meses, tendo encontrado somente $11 \%$ de susceptiveis.

A grande disparidade entre as percentagens de positividade obtidas em vários países da América Latina, que vão, em crianças de 5 a 9 anos, desde $0 \%$ em Barbados e $18 \%$ em Trinidad até $97 \%$ em Santiago ${ }^{5,6,9,15}$, dificulta a realização de estudos comparativos. Estas variações podem ter decorrido de diferentes critérios na escolha da amostragem, além de outros fatores ainda não bem esclarecidos ${ }^{17}$.

O fato de não ter sido possivel correlacionar antecedentes positivos para rubéola, com presença ou ausência de anticorpos circulantes nas crianças, nos dá uma idéia das dificuldades encontradas ao se tentar traçar um perfil epidemiológico da rubéola, baseando-se simplesmente em informação deste tipo.

Quanto ao sarampo e à caxumba, a alta positividade de anticorpos contra estes vírus reflete a grande incidência dessas doenças na população estudada, confirmando os trabalhos de Godoy ${ }^{8}$ e Niederman e col. ${ }^{14}$. Na faixa etária examinada (6-12 anos), apenas $11,8 \%$ e $20,6 \%$ eram susceptiveis, respectivamente, ao sarampo e à caxumba. Os resultados encontrados são mais elevados do que os observados em vários outros países 1, 2, 8, 18, 20.

Existe uma boa concordância entre história pregressa de sarampo e caxumba e presença de anticorpos circulantes contra estes vírus $(95,3 \%$ e $91,7 \%$, respectivamente). Entretanto, quando comparamos a ausência de vacinação ou de história de sarampo ou caxumba no passado e positividade de anticorpos circulantes no sangue, para estes vírus, encontramos importantes discrepâncias $\quad(51,8 \%$ e $61,4 \%$, respectivamente), explicadas talvez por infecções subclínicas ou atípicas, erros diagnósticos, ou mesmo erro de informação dos pais. Este fato foi observado também por Veronesi e col. ${ }^{21}$. Pela sua grande freqüência, acreditamos ser necessário o uso, em larga escala, de vacinas para a prevenção destas infecções em nosso meio, poupando-se, assim, muitas crianças das complicações que possam ocasionar. 
CARvalho, R. P. de S. et al. - Anticorpos para os virus da rubéola, do sarampo e da c zxumba em criancas de São Paulo. Brasil. Rev. Saúde públ., S. Paulo, 10:279-84, 1976.

Carvalho, R. P. de S. et al. - [Rubella. measles and mumps serum antibodies in children of S. Paulo, Brazil]. Rev. Saúde públ., S. Paulo, 10:279-84, 1976.

Summary: One hundred and sixty high socio-economic level, 6-12 year old children, attending a primary school, were tested in 1969 for rubella, measles and mumps $H I$ antibodies. A $49.3 \%$ positivity for rubella antibodies, $88.2 \%$ for measles and $79.4 \%$ for mumps were found. A good correlation was observed between a positive history of clinical disease in the past and detectable serum antibodies for measles and mumps $(95.3 \%$ and $91.7 \%$, respectively). Quite on the contrary was observed when the history of measles and mumps disease or immunization in the past were negative, as $51.8 \%$ and $61.4 \%$ of these children, respectively, presented antibodies. As regards mbella, no correlation was obtained as the great majority of the parents was unable to give information on this disease in the past.

UNITERMS: Seroepidemiologic study, nomal children. Rubella-measlesmumps.

\section{REFERENCIAS BIBLIOGRÁFICAS}

1. BLACK, F. L. - Measles antibody prevalence in diverse populations. Amer. J. Dis. Child., 103:242-9, 1962.

2. BLACK, F. L. \& HOLGHTON, W. J. The significance of mumps hemagglutinin inhibition titers in normal populations, Amer. J. Epidem., 85: 101-7, 1967.

3. CANDEIAS, J. A. N. \& ROSENBURG, C. P. - Inquérito sorológico para rubéola em professoras do município de São Paulo, Brasil. Rev. Saride públ., S. Paulo, 8:391-8, 1974.

4. COTILlo, Z. L. G - Anticorpos neutralizantes contra rubéola num grupo de gestantes de São Paulo. São Paulo, 1967. (Tese - Faculdade de Farmácia e Bioquimica da USP).

5. DOWLE, W. R et al. - WHO collaborative study on the sero-epidemiology of rubella in Caribbean and Middle and South American populations in 1968. Bull. Org. mond. Sante, 42:419-22, 1970 .

6. EVANS, A. S et al. - A health and seroepidemiological survey of a community in Barbados. Int. $J$ Epidem., $3: 167-75,1974$

7. FREESTONE, D $S$. et a1. - History of infection and immunity to rubella. Amer. J. Epidem., 96:70-3, 1972.
8. GODOY, C. V. F. - Contribuicão para o estudo imunologico das infeccóes pelo virus da carumba. São Paulo, 1967. (Tese - Faculdade de Medicina da USP).

9. GOLUBJATNIKOV, $R$. et al. - Anticuerpos inhibidores de la hemaglutinación para sarampión, rubéola y parotiditis. Investigación de su prevalencia en una comunidad de la meseta de México. Salud pübl. Méx., 12:603-9, 1970

10. GOULD, K. L. et al. - The epidemiology of measles in the U.S. Trust Territory of the Pacific Islands. Amer. J. publ. Hlth, 61:1602-14, 1971.

11. HILLARY, I. B. - Rubella serological survey on Irish school children. Irish J. med. Sci., 140:295-304, 1971.

12. LERMAN, S. J. et al. - Accuracy of rubella history. Ann. intern. Med., 74:97-8, 1971 .

13. MeLEAN, D. M. - The rubella situation in Canada - 1972. Canad. $J$. publ. Hith, 63:385-91, 1972.

14. NIEDERMAN, J. C. et al. - A nation-wide serum survey of Brazillan military recruits, 1964. II. Antibody patterns with arbovirus, poliovirus, measles and mumps. Amer. J. Epidem., 86:319-29, 1967. 
CARvalHo, R. P. de S. et al. - Anticorpos para os virus da rubéola, do sarampo e da caxumba em criansas de São Paulo. Brasil. Rer. Salude puibl., S. Paulo, 10:279-84, 1976.

15. ORDOÑEZ, B. R. - Frecuencia de la rubéola en México: investigación epidemiologica. Salud pübl. Méx., 11: 731-9, 1969.

16. RAWLS, W. E. et a1, - WHO collaborative study on the sero-epidemiology of rubella. Bull. Wld Hith Org., 37:79-88, 1967.

17. RIZZATO, A. B. P. - Inquérito sorologico para rubéola em escolares do sexo feminino do distrito sede de Botucatu (SP) em 1973. Botucatu, 1973. (Tese - Facuidade de Ciências Médicas e Blológicas de Botucatu).

18. ROBBINS, F. C. - Epidemiologia e importancia clinica de la parotiditis infecciosa en el hombre. Bol. Ofic. sanit. panamer., 63:299-306, 1967.

19. SCHATZMAYR, H. G, \& MESQUITA, J. A. - Avaliação clínica e sorológica da vacinação contra a rubéola.
Bol. Epldem., Rio de Janeiro, 1:145-9, 1969.

20. SNYDER, MI. J. et al. - Observations on the seroepidemiology of measles. Amer. J. Dis. Child., 103:250-1, 1962.

21. VERONESI, $R$, et al. - Resultados preliminares de estudos clínicos e laboratoriais sobre a eficácia da vacinação contra o sarampo em criancas de São Paulo. Rev. Hosp. Clin. Fac. Med. S. Paulo, 16:397-405, 1961.

22. VERONESI, R. et al. - Revisão de da. dos da epidemiologia e etiologia do sarampo e subsidios para a vacinacão contra a doença. Arq. Fac. Hig. S. Paulo, 17:135-204, 1963.

23. VERONESI, $R$. et al. - Resultados do primeiro inquérito sorológico da rubéla entre 100 crianças de uma creche de São aPulo. Bol. epidem., Rio de Janeiro, 1:89-93, 1969.

Recebido para publicaşa em 17/03/1975 Aprovado para publicasáo em 1'/06/1970 